\title{
TRAUMATIC MYIASIS OF HORSES CAUSED BY WOHLFAHRTIA MAGNIFICA
}

\author{
R. FARKAS ${ }^{1 *}$ and GY. KÉPES ${ }^{2}$ \\ ${ }^{1}$ Department of Parasitology and Zoology, Faculty of Veterinary Science, Szent István \\ University, H-1400 Budapest, P.O. Box 2, Hungary; ${ }^{2}$ Nagykarácsony, Hungary
}

(Received January 23, 2001; accepted May 17, 2001)

\begin{abstract}
A survey was carried out in three stud farms with grazing animals, in order to gather data on the prevalence and clinical manifestation of, and the fly species involved in, traumatic myiasis of horses in Hungary. This parasitic disease was recorded in each farm. On the whole, 9.0\% (14) of the inspected horses were infested with fly larvae. The affected horses had one infested lesion only, located at the mucosa of the vulva or the vaginal vestibule. The clinical symptoms depended on the age of infestation. Wohlfahrtia magnifica (Diptera: Sarcophagidae) was the only myiasis-causing fly species identified. It was assumed that unknown volatile chemicals might be responsible for the attraction of gravid females to the undamaged vulvar region. These odours are supposed to be produced during different physiological and/or pathological events associated with oestrus, prolonged puerperal period or inflammation of tissues. Daily inspection of grazing horses and early treatment of the affected areas are needed to avert significant damage to the infested horses.
\end{abstract}

Key words: Traumatic myiasis, Wohlfahrtia magnifica, wohlfahrtiosis, horse, Hungary

Traumatic myiasis, also called 'wound myiasis', 'strike' or 'fly strike', is the infestation of living humans and vertebrate animals with fly larvae which feed and develop on the cutaneous tissues and cause traumatising injury (Hall and Farkas, 2000). Some fly species of two families (Diptera: Calliphoridae and Sarcophagidae) are responsible for traumatic myiasis in Europe (Hall, 1997). In Southern and Eastern Europe Wohlfahrtia magnifica (Schiner, 1862) (Diptera: Sarcophagidae), an obligate larval parasite of live warm-blooded vertebrates, was found to be the major myiasis-causing fly species in the vast majority of animals inspected (Ruiz Martinez et al., 1987, 1991; Lehrer and Verstraeten, 1991; Farkas et al., 1997).

Traumatic myiasis can be one of the most important parasitic diseases of grazing livestock in Hungary, causing severe animal health problems and economic losses (Farkas and Hall, 1998). Sheep are the most affected animal hosts (Farkas et al., 1997), but traumatic myiasis occurs also in geese (Farkas et al.,

*Corresponding author; E-mail: rfarkas@univet.hu; Fax: +36 (1) 478-4193 
2001), cattle and pigs (Farkas, unpublished). In a questionnaire survey of Hungarian veterinarians twenty-two per cent of respondents reported that traumatic myiasis occurs in horses, too (Farkas and Hall, 1998).

In the literature, there is little detailed information on horses affected by traumatic myiasis. Kurtpinar (1950) and Zumpt (1965) only mentioned that horses could be infested by $W$. magnifica. Zumpt (1965) wrote that the larvae of Lucilia sericata (Meigen) (Diptera: Calliphoridae) are also known as facultative parasites in horses, and myiasis due to Chrysomya bezziana (Villeneuve) (Diptera: Calliphoridae) had been found in this host species. Later, Navidpour et al. (1996) reported that one horse was affected in an outbreak of myiasis caused by C. bezziana.

The aim of the study reported here was to gather basic data on the prevalence and clinical manifestation of, and the fly species involved in, traumatic myiasis of horses in Hungary.

\section{Materials and methods}

Three stud farms with mares and foals were included in the survey. The farms are located in three counties of Hungary. The size of the stocks ranged from 19 to 79 thoroughbred (Gidrán and English) and half-bred (Hungarian, Kisbér etc.) horses. The age of the horses ranged from three months to 16 years. The animals were grazed on pastures where they were supplied with hay and water.

In two farms (Marócz-puszta and Üllö) the horses were inspected daily, from April to October, for the presence of clinical signs of traumatic myiasis. In the third farm (Elöszállás) the inspection of animals was carried out twice a week only. If the local workers or owners observed any horses infested with fly larvae, they informed the authors immediately who visited the farm within 24 hours. The body site and clinical manifestation of each case were recorded. All larvae were removed from the lesions. The larvae per wound were collected in $80 \%$ alcohol, and submitted for laboratory examination where they were identified and counted. All larval stages were counted. After removing the maggots the wounds were treated topically with a pyrethroid spray. If any flies appeared around the wounds, their behaviour was observed.

During the period of work reported the weather was mainly sunny with daily temperatures ranging from $17{ }^{\circ} \mathrm{C}$ to $36^{\circ} \mathrm{C}$.

\section{Results}

Traumatic myiasis was recorded in each stud farm in July and August. Taken as whole, $9.0 \%(14 / 163)$ of the inspected horses became infested with fly larvae. The total number of infested animals was three in Üllö, five in Marócz- 
puszta and six in Elöszállás, but only one or two animals in a stud had active traumatic myiasis at the same time. All of the cases occurred in mares. Even a small infested wound disturbed the animals considerably. The animals were restless. They lashed their tails much more often than the uninfested horses and very frequently stamped their hind legs on the ground. They tried to reach their vulvar region with their mouth. Each affected horse had only one wound filled with fly larvae which were located only at the mucosa of the vulva or vaginal vestibule (Figs 1, 2 and 3).

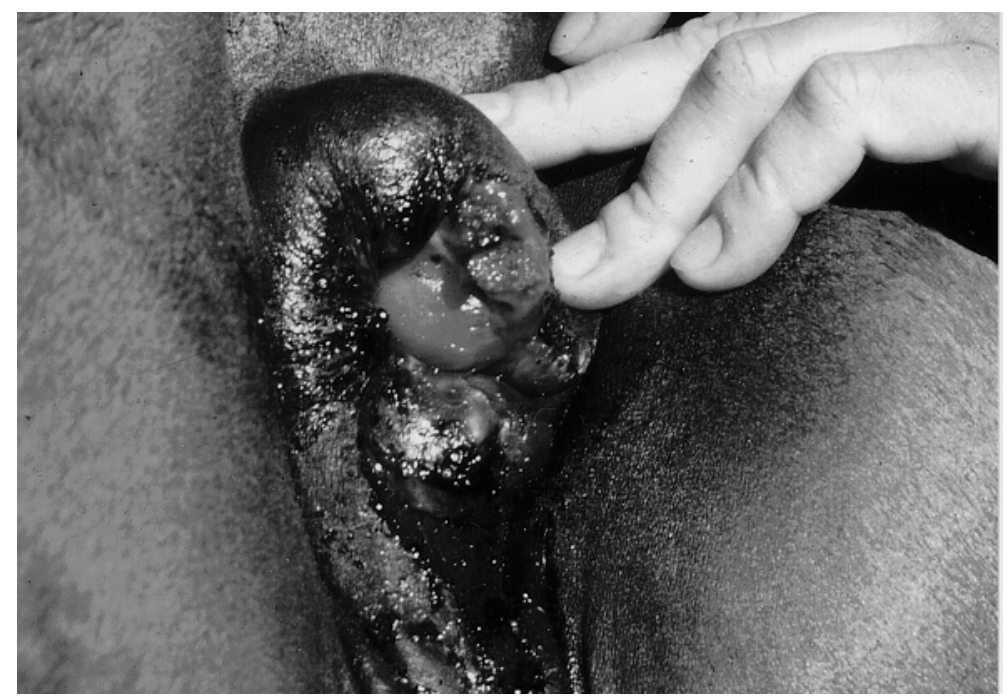

Fig. 1. Early infestation of the vulva in a horse caused by Wohlfahrtia magnifica

The clinical symptoms depended on the age of infestation. In very early cases no abnormalities were seen, or oedema of tissues around the vulva was the only finding. Sometimes moderate bleeding from the vulva was observed (Fig. 1). Closer examination was needed to detect the young fly larvae embedded in the mucosa of the vulva (Fig. 1) or in the dorsal part of the vaginal entrance (Fig. 2). In more advanced cases, a much bigger, about palm-sized irregular wound, filled with a huge number of larvae, was visible in the vulvar region (Fig. 3). The surrounding skin was wet with blood and exudate which spilt freely over the edges of the lesion. Several flies stayed and fed on and around the most severe wounds. Usually the affected areas had no typical putrefactive odour. The wounds contained a pulsating mass of larvae. The larvae were packed tightly together in a screwworm manner, with their heads buried deep in the tissues, and the posterior segments exposed only with their external openings to the respiratory system (Fig. 2). In some cases, a range of different developmental larval stages formed distinct foci in the wound. Disturbed larvae retracted deeper into the surrounding tissues, and were 
difficult to remove, even by forceps. The number of larvae per lesion ranged from 12 to 367 . W. magnifica was the only myiasis-causing fly species identified.

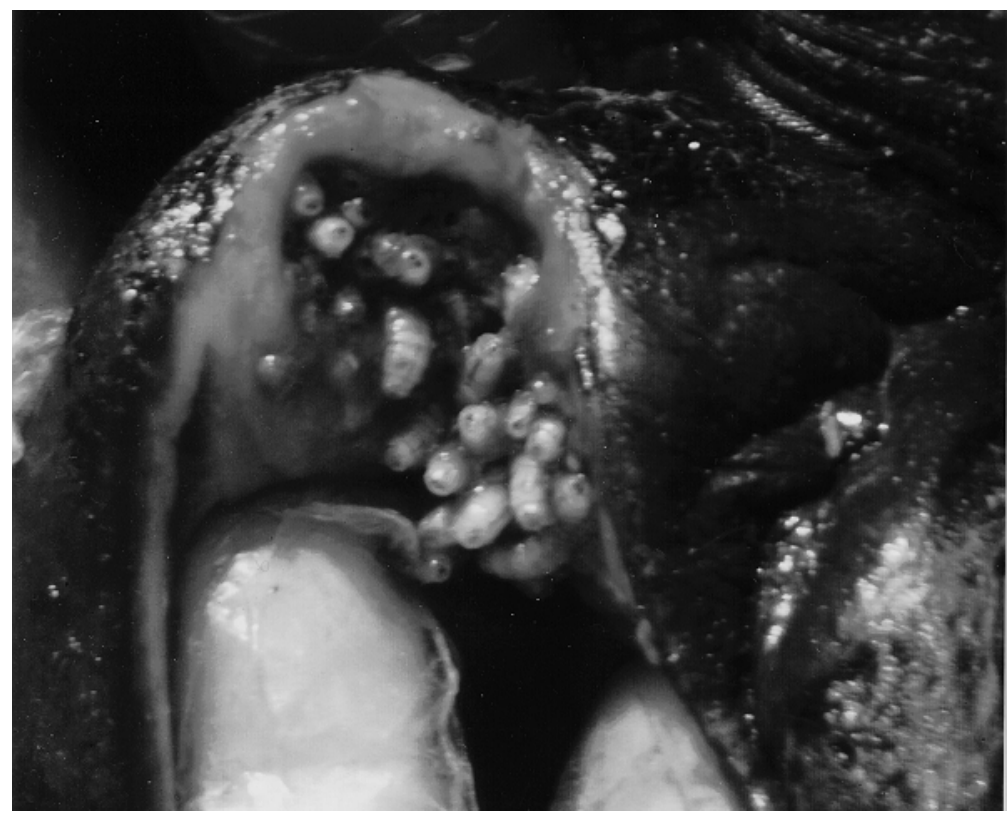

Fig. 2. Larvae of $W$. magnifica embedded in the vaginal vestibule of a horse

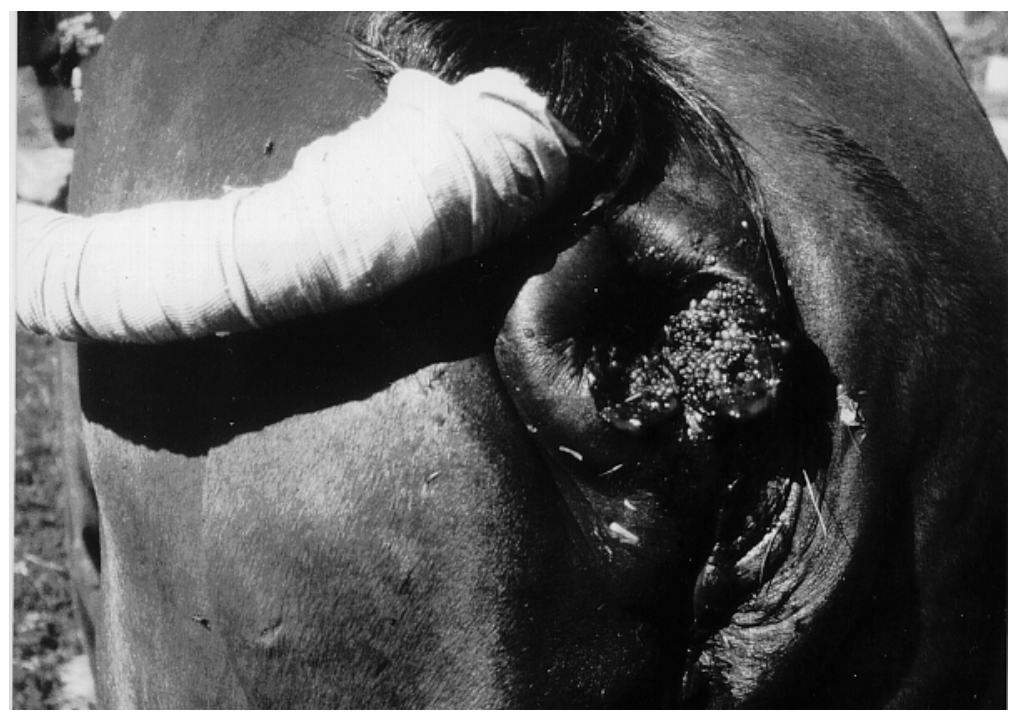

Fig. 3. Severe wohlfahrtiosis in the vulvar region of a horse due to multiple infestations 
After removing all the larvae from the most heavily infested wounds, cavernous lesions with irregular, ragged edges were seen (Fig. 4). The mild wounds healed up without any tissue destruction after topical treatment. The most heavily infested animals were found in Elöszállás, where the grazing horses were not inspected daily, but only twice a week. These horses did not show complete wound healing, cicatrization was observed, which resulted in deformation of the genital entrance region (Fig. 5).

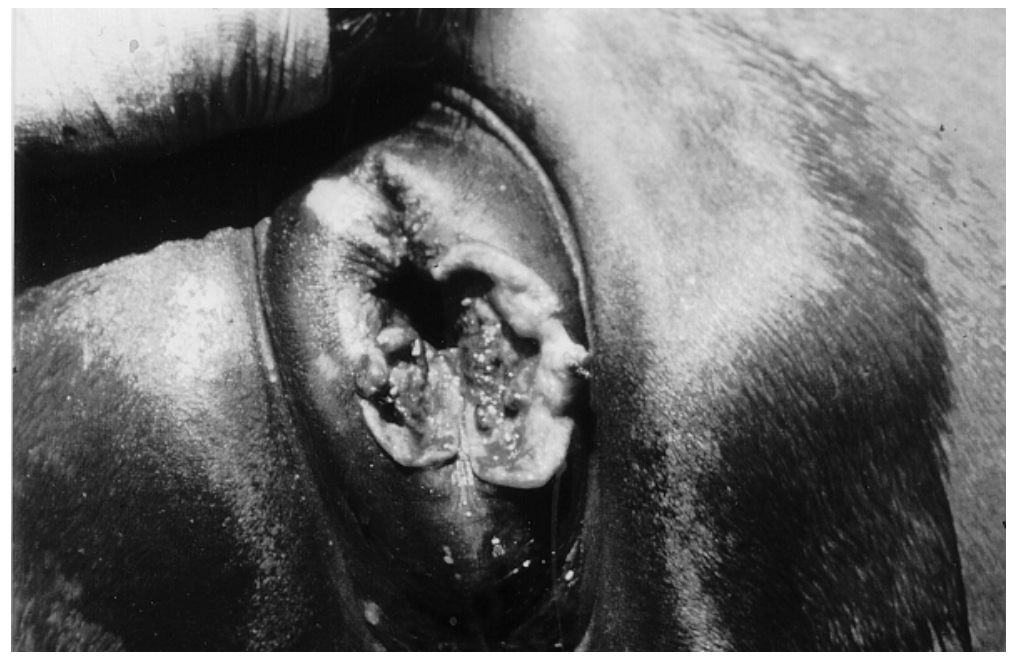

Fig. 4. Tissue destruction in the vulva after removing the larvae of W. magnifica

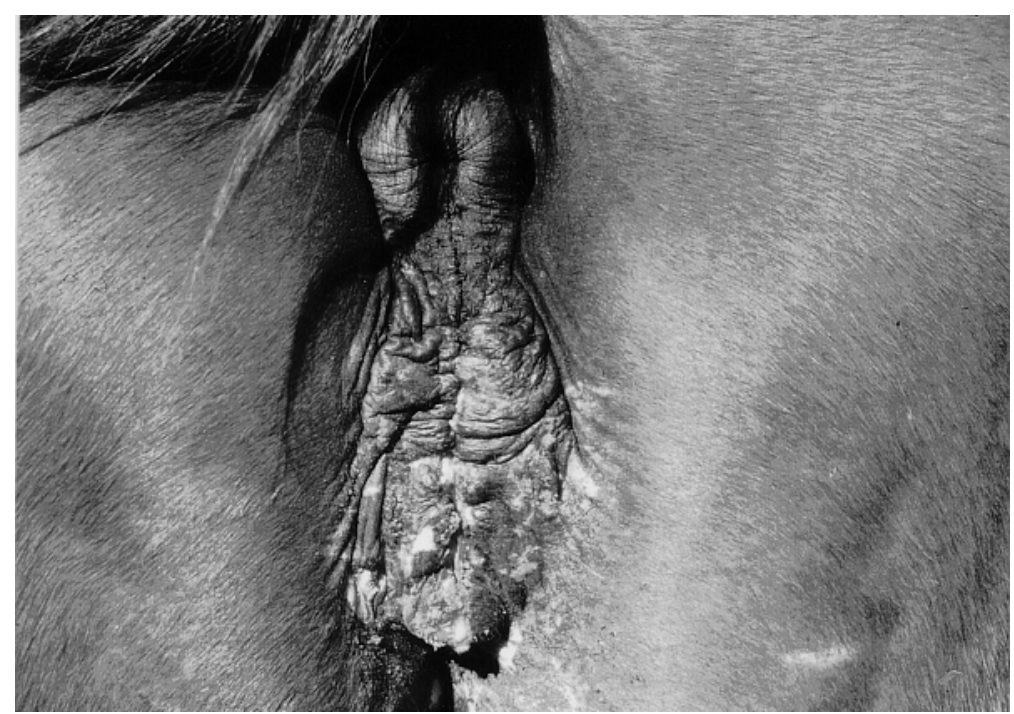

Fig. 5. Cicatrization and deformation of the vulva in a horse due to wohlfahrtiosis 


\section{Discussion}

This study has demonstrated that traumatic myiasis occurs in grazing horses in Hungary during the summer months, which had only been reported in a questionnaire survey of Hungarian veterinarians (Farkas and Hall, 1998). Based on the identification of larvae collected from the lesions of affected animals, it can be concluded that at least one species of fly, W. magnifica is responsible for this parasitic disease of horses. These results confirm those observations in which $W$. magnifica was found to be the most important species of myiasiscausing flies in Hungary in sheep and geese (Hall et al., 1995; Farkas et al., 1997, 2001). However, it cannot be excluded that other species, such as the blowfly, the greenbottle ( $L$. sericata) can also cause traumatic myiasis of horses in Hungary. In the present study, a huge number of Lucilia adults were encountered on the pasture, mainly around the myiatic lesions of horses. Zumpt (1965) mentioned that also the larvae of this species can be facultative parasites of horses, and a few cases of myiasis caused by L. sericata have been found in sheep and geese also in Hungary (Farkas et al., 1997, 2001).

Infestation with larvae of $W$. magnifica only occurred at the external genital region of mares. It has been found that wohlfahrtiosis is located most frequently in the vulvar region in female sheep (Ruiz Martinez et al., 1987, 1991; Farkas et al., 1997) and camels (Hadani et al., 1989; Valentin et al., 1997) as well. In our cases Wohlfahrtia larvae were deposited onto seemingly uninjured mucous membranes of the vulva or vaginal vestibule. Wounds or injuries of affected areas are apparently not a prerequisite for the establishment of wohlfahrtiosis, which has been supposed by some scientists (Hadani et al., 1971; Ruiz Martinez et al., 1987). So far, there has been scant information about the factors which contribute to the development of wohlfahrtiosis. Although it is known that myiasis-causing flies are mainly attracted to their hosts by odours (Hall, 1995), the sources and the chemical properties of the odours which might have attractive potential for Wohlfahrtia females are not known yet. We assume that these may be volatile chemicals, possibly produced during different physiological and/or pathological processes related to the internal or external genital organs of the hosts. The breakdown products of urine or genital discharges associated with oestrus, prolonged puerperal period or inflammation of tissues can attract gravid female flies, and stimulate them to larviposition. It has been demonstrated that changes of microbiological communities of the skin and mucous membranes of the external genitals of sheep result in the production of volatile chemicals which can be responsible for the initiation of wohlfahrtiosis (El-Khoga, 1994; Tóth et al., 1998).

The clinical features observed in affected horses resembled those described in sheep and camels (Farkas et al., 1997; Valentin et al., 1997). Despite the fact that only a few dozen first instar larvae of $W$. magnifica were laid in an animal in the initial phase of wohlfahrtiosis, damage to the host was rapid and 
considerable due to the feeding activity of the larvae. The fast-growing larvae formed pulsating masses in the wounds, which progressively enlarged. In some cases, different larval stages were found together, indicating that Wohlfahrtia females had been attracted to lesions already containing larvae of this species, leading to superinfestation of wounds. The cavities of these lesions were enlarged and extended laterally and deep into the subcutaneous tissues (Fig. 4). After healing, these areas were markedly deformed (Fig. 5), possibly interfering with future foaling.

For the above-mentioned reasons infestation of horses with Wohlfahrtia larvae can present severe health problems. Frequent, daily inspection of grazing horses, and early treatment of infested areas are needed to avert significant damage to the affected horses. In general, larvicidal drugs formulated for topical application are considered to be effective for killing the larvae. However, there is a need for novel control methods, because the chemicals do not have residual or repellent activity, and delay wound healing (Farkas et al., 1996). The main goal is to prevent the infestation of horses and other host species with larvae of this myiasis-causing fly species. The field use of traps baited with effective attractants to gravid females might reduce the number of flies on pasture (Hall et al., 1995). Based on the preliminary results of immunological studies of Wohlfahrtia infestation in sheep, vaccination may offer a potential method for the future prevention of wohlfahrtiosis (Farkas et al., 1998).

\section{Acknowledgements}

The financial support of the Hungarian Scientific Research Fund (T 026599) and of the Hungarian Ministry of Education (FKFP 0537/99) is gratefully acknowledged.

\section{References}

El-Khoga, J. M. (1994): Myiasis: a consequence or a cause of skin bacterial alterations. Ph.D. Dissertation, Eötvös Loránd University, Budapest.

Farkas, R. and Hall, M. J. R. (1998): Prevalence of traumatic myiasis in Hungary: a questionnaire survey of veterinarians. Vet. Rec. 143, 440-443.

Farkas, R., Hall, M. J. R., Dániel, M. and Börzsönyi, L. (1996): Efficacy of ivermectin and moxidectin injection against larvae of Wohlfahrtia magnifica (Diptera: Sarcophagidae) in sheep. Parasitol. Res. 82, 82-86.

Farkas, R., Hall, M. J. R. and Kelemen, F. (1997): Wound myiasis of sheep in Hungary. Vet. Parasitol. 69, 133-144.

Farkas, R., Hornok, S. and Gyurkovszky, M. (1998): Preliminary studies on humoral immune response of sheep to wohlfahrtiosis. Vet. Parasitol. 75, 279-284.

Farkas, R., Szántó, Z. and Hall, M. J. R. (2001): Traumatic myiasis of geese in Hungary. Vet. Parasitol. 95, 45-52. 
Hadani, A., Rabinsky, R., Shimshoni, A. and Vishinsky, Y. (1971): Myiasis caused by Wohlfahrtia magnifica (Schiner) in sheep on the Golan Heights. Refuah Vet. 28, 25-33.

Hadani, A., Yaakov, B. B. and Rosen, Sh. (1989): Myiasis caused by Wohlfahrtia magnifica Schiner, (1862) in the Arabian camel (Camelus dromedarius) in the Peninsula of Sinai. Rev. Élev. Méd. Vét. Pays Trop. 42, 33-38.

Hall, M. J. R. (1995): Trapping the flies that cause myiasis: their responses to host stimuli. Ann. Trop. Med. Parasitol. 89, 333-357.

Hall, M. J. R. (1997): Traumatic myiasis of sheep in Europe: a review. Parasitologia 39, 409-413.

Hall, M. J. R. and Farkas, R. (2000): Traumatic myiasis of humans and animals. In: Papp, L. and Darvas, B. (eds) Contributions to a Manual of Palaearctic Diptera. Science Herald, Budapest, pp. 751-768.

Hall, M. J. R., Farkas, R., Kelemen, F., Hosier, M. J. and El-Khoga, J. M. (1995): Orientation of agents of wound myiasis to hosts and artificial stimuli in Hungary. Med. Vet. Entomol. 9, $77-84$.

Kurtpinar, H. (1950): Spesific bir myiasis amili olan Wohlfahrtia magnifica (Schiner 1862) in Türkiye ehli hayvanler indaki rolu. Türk. vet. Dern. Derg. Yil. 7 pp.

Lehrer, A. Z. and Verstraeten, C. (1991): Expension parasitologique et géographique de Wohlfahrtia magnifica (Schiner) (Diptera: Sarcophagidae) en Roumanie. Bull. Rech. Agr. Gembloux 26, 563-567.

Navidpour, S. H., Hoghooghi-Rad, N., Goodarzi, H. and Pooladgar, A. R. (1996): Outbreak of Chrysomya bezziana in Khoozestan province, Iran. Vet. Rec. 139, 217.

Ruiz Martinez, I., Cruz, S. M. D., Rodriguez, R. B., Lopez, D. M., Parra, M. S. and Navio, F. A. (1987): Myiasis caused by Wohlfahrtia magnifica in Southern Spain. Isr. J. Vet. Med. 43, 34-41.

Ruiz Martinez, I., Cruz, S. M. D., Rodriquez, R. B., Jimenez, P. J. M. and Lopez, D. M. (1991): Myiasis caused by Wohlfahrtia magnifica in sheep and goats in Southern Spain. II. Effect of age, body region and sex on larval infestation. Isr. J. Vet. Med. 46, 64-68.

Tóth, E., Farkas, R., Márialigeti, K. and Mokhtar, I. S. (1998): Bacteriological investigations on wound myiasis of sheep caused by Wohlfahrtia magnifica (Diptera: Sarcophagidae). Acta Vet. Hung. 46, 219-229.

Valentin, A., Baumann, M. P. O., Schein, E. and Bajanbileg, S. (1997): Genital myiasis (wohlfahrtiosis) in camel herds of Mongolia. Vet. Parasitol. 73, 335-346.

Zumpt, F. (1965): Myiasis in man and animals in the Old World. Butterworths, London, xv +267 pp. 